\title{
[4,4'-Bipyridine]-1,1'-diium tricyanomethanide as a nanostructured molten salt and its catalytic application in the synthesis of tetrahydrobenzo[b]pyrans, amido and aminoalkyl naphthol derivatives
}

${ }_{4} \quad$ Mohammad Ali Zolfigol, * Meysam Yarie, Saeed Baghery

Department of Organic Chemistry, Faculty of Chemistry, Bu-Ali Sina University, Hamedan 6517838683, Iran

\begin{abstract}
An efficient process for the synthesis of tetrahydrobenzo[b]pyrans derivatives was attained via the reaction of dimedone, various aldehydes and malononnitrile using [4,4'-Bipyridine]-1,1'-diium tricyanomethanide $\left\{\left[4,4^{\prime}-\mathrm{BPyH}\right]\left[\mathrm{C}(\mathrm{CN})_{3}\right]_{2}\right\}$ as a green mild nano structure molten salt catalyst under solvent-free conditions at room temperature. To further investigation on catalytic properties of $\{[4,4$ '$\left.\mathrm{BPyH}]\left[\mathrm{C}(\mathrm{CN})_{3}\right]_{2}\right\}$, it was used in the synthesis of amido and aminoalkyl naphthol derivatives under solvent-free conditions at $75{ }^{\circ} \mathrm{C}$. $\left\{\left[4,4^{\prime}-\mathrm{BPyH}\right]\left[\mathrm{C}(\mathrm{CN})_{3}\right]_{2}\right\}$ has advantages such as cleaner reaction profile, benign characters, cost effectiveness, reusability of the catalysts and being in agreement with the green chemistry protocols.
\end{abstract}

Keywords: Bifunctional nano structure molten salt; [4,4'-Bipyridine]-1,1'-diium tricyanomethanide; Tetrahydrobenzo[b]pyrans; Amidoalkyl naphthol; Aminoalkyl naphthol; Solvent-free conditions.

\footnotetext{
*Corresponding Author: Fax: +988138257407

E-mail: zolfi@basu.ac.ir and mzolfigol@yahoo.com (M.A.ZZolfigol).
} 


\section{Introduction}

It is generally acknowledged that there is an increasing significance for more accessible ecofriendly approaches in the chemical and heterocyclic synthesis and pharmaceutical industries. This advanced improvement called 'green chemistry' or 'ecological technology' needs a model alteration taken from customary ideas of procedure efficiency, that focuses chiefly on yield of product, to one that assigns economic value, removing waste and avoiding the usage of dangerous and toxic materials [1]. Room-temperature molten salts (RTMSs), named as room-temperature ionic liquids, (RTILs), which are immiscible or only partially miscible with water, are promising to be replacements of usual organic solvents. Molten salts (MSs) have significant potentials such as electrolyte substances. The molten salts, recently termed ionic liquids, have drawn much consideration in numerous scientific fields [2]. Molten salts or ionic liquids are usually liquid electrolytes combined of ions. More recently, the melting point pattern has been introduced to make identification of molten salts (very corrosive medium, high-melting and highly viscous) and ionic liquids (relatively low viscosity and liquid below $100{ }^{\circ} \mathrm{C}$ ) [3] possible. Molten salts have noteworthy potentials such as electrolyte substances. Scientists have performed experiments to change solid salts into liquids using appropriate substances and also efforts have been made to polymerize molten salts into solid films. Numerous investigations have been done to improve a superb ion-conductive matrix, among which polymerization of molten salts is a promising process to create highly ion-conductive polymer films $[4,5]$. Besides the polarization procedure applied, molecular dynamics simulations of molten salts in which polarization effects are included have exposed that the mobility of liquids increases [6, 7]. Furthermore, other uses of molten salt are in methane reforming and methanol steam reforming $[8,9]$.

Multicomponent reactions (MCRs) demonstrate a very efficient and economic approach to build up complex structures in a single synthetic process from very simple reactants, most of the time in a onepot reaction [10]. Such reactions display methodological ease, high selectivity and high atom economy because of the formation of carbon-carbon and carbon-heteroatom bonds in a single step [11]. MCRs are usually very high yielding being a one-pot process and are basically fully different from two-component reactions [12]. One such MCRs is the one-pot three-component tandem Knoevenagel-Michael cyclocondensation synthesis of tetrahydrobenzo $[b]$ pyran derivatives that is one of the significant types of organic compounds. Tetrahydrobenzo[b]pyran derivatives are significant compounds that have fullfledged remarkable consideration in past years owing to their varied range of biological activities [13] for example diuretic, anticancer, anti-anaphylactic activities and anticoagulant [14]. Correspondingly, tetrahydrobenzo[b]pyrans are applied as cognitive enhancers for the treatment of neurodegenerative 
illness, for instance Alzheimer's, Huntington's, Parkinson's illnesses and Down's syndrome in addition to the treatment of myoclonus and schizophrenia [15]. Owing to the significance of tetrahydrobenzo $[b]$ pyrans, various methodologies have been reported for its synthesis in past years [16].

Other significant types of organic compounds are the 1-(amino or amidoalkyl)-2-naphthol derivatives, called Betti bases [17]. Recently, attention to the chemistry of the Betti base [18] has increased because of their attractive catalytic [19] and biological [20] properties. These compounds can be transformed into derivatives having hypotensive, antibacterial and bradycardiac activities [21]. There are various processes described for the synthesis of 1-(amino or amidoalkyl)-2-naphthols containing saccharin sulfonic acid (SASA) [22], nano-S (S8-NP) [23], [Msim]Cl or [Dsim]Cl or [Msim] $\mathrm{AlCl}_{4}[24]$, $\left\{[\mathrm{HMIM}] \mathrm{C}(\mathrm{CN})_{3}\right\}[25],\left\{[1,4-\mathrm{DHPyrazine}]\left[\mathrm{C}\left(\mathrm{NO}_{2}\right)_{3}\right]_{2}\right\}$ [26], un-catalyzed in water [27] and sulfanilic acid-functionalized silica-coated magnetite nanoparticles [28].

Following our previous studies linked to the design, synthesis, applications and knowledge-based development of novel solid acids and inorganic acidic salts [29], novel nano structured, green and benign ionic liquids, molten salts and organo-catalysts for organic functional group transformations and as a section of our continuous work to the development of environmentally benign synthetic procedures for MCRs to synthesize various biologically significant heterocyclic compounds [30], herein we wish to report the synthesis of an efficient and reusable bifunctional nano structure molten salt catalyst, namely [4,4'-bipyridine]-1,1'-diium tricyanomethanide $\left\{[4,4\right.$ '- $\left.\mathrm{BPyH}]\left[\mathrm{C}(\mathrm{CN})_{3}\right]_{2}\right\} \quad($ Scheme 1) [31] and its application for the highly effective synthesis of tetrahydrobenzo[ $b]$ pyrans and amido or aminoalkyl naphthol derivatives under solvent-free conditions (Scheme 2).

$>$ Scheme $1<$

$>$ Scheme $2<$

\section{Experimental}

The materials were purchased from Merck, Fluka and Sigma-Aldrich and were used without any additional purification. All reactions were monitored by thin layer chromatography (TLC) on gel F254 plates. Spectrometer $\left({ }^{1} \mathrm{H}\right.$ NMR $400 \mathrm{MHz}$ and ${ }^{13} \mathrm{C}$ NMR 100) in pure deuterated DMSO with tetramethylsilane (TMS) as the internal standard. Characteristics of the synthesized catalyst were determined by IR, ${ }^{1} \mathrm{H}$ NMR, ${ }^{13} \mathrm{C}$ NMR, mass, X-ray diffraction patterns (XRD), scanning electron microscopy (SEM) and transmission electron microscopy (TEM), thermo gravimetric (TG) and derivative thermal gravimetric (DTG) analysis. X-ray diffraction (XRD) patterns of all catalysts were performed on a APD 2000, Ital structure with $\mathrm{Cu} \mathrm{K}$ _radiation $(\mathrm{k}=0.1542 \mathrm{~nm})$ operating at $50 \mathrm{kV}$ and $20 \mathrm{~mA}$ in a $2 \mathrm{~h}$ 
range of $10-70^{\circ}$ with step size $0.01^{\circ}$ and time step $1.0 \mathrm{~s}$ to assess the crystallinity of the catalyst. Fourier transform-infrared spectra of the samples were recorded on a Perkin-Elmer FT-IR spectrometer 17259 using $\mathrm{KBr}$ disks. Thermo gravimetric analyses using a Perkin-Elmer TGA were performed on catalysts. The weight loss about $152{ }^{\circ} \mathrm{C}$ was identified. The SEM analyses were done with a TESCAN/MIRA with a maximum acceleration voltage of the primary electrons between 10 and $15 \mathrm{kV}$. Transmission electron microscope, TEM measurements were carried out on a Philips CM10 analyzer. Operating at $120 \mathrm{kV}$.

General procedure for the synthesis of bifunctional nano strcture molten salt catalyst: [4,4'bipyridine $]-1,1^{\prime}$-diium tricyanomethanide $\left\{\left[4,4^{\prime}-\mathrm{BPyH}\right]\left[\mathrm{C}(\mathrm{CN})_{3}\right]_{2}\right\}$

The NMS $\left\{\left[4,4^{\prime}-\mathrm{BPyH}\right]\left[\mathrm{C}(\mathrm{CN})_{3}\right]_{2}\right\}$ as a green catalyst was synthesized according to our previously reported procedure [31]. A pale yellow solid was prepared in high purity and then the physical data of this identified NMS was found to be identical with the reported procedure (Scheme 1).

\section{[4,4'-bipyridine $]-1,1^{\prime}$-diium tricyanomethanide $\left\{\left[4,4^{\prime}-\mathrm{BPyH}\right]\left[\mathrm{C}(\mathrm{CN})_{3}\right]_{2}\right\}$}

Pale yellow solid; M.p: $>300{ }^{\circ} \mathrm{C}$; Yield: 97\% (1.641 g); Spectral data: IR (KBr): $v_{\max }=3411$, 3070, 3025, 2927, 2169, 2082, 1662, 1486, $1218 \mathrm{~cm}^{-1}$; ${ }^{1} \mathrm{H}$ NMR (400 MHz, DMSO- $\left.d_{6}\right): \delta_{\mathrm{ppm}}=6.92(\mathrm{~d}$, $4 \mathrm{H}, J=0.8 \mathrm{~Hz}, \mathrm{ArH}), 7.12(\mathrm{~d}, 4 \mathrm{H}, J=0.8 \mathrm{~Hz}, \mathrm{ArH}), 7.63(\mathrm{~s}, 2 \mathrm{H},-\mathrm{NH}) ;{ }^{13} \mathrm{C}$ NMR $(100 \mathrm{MHz}, \mathrm{DMSO}-$ $\left.d_{6}\right): \delta_{\mathrm{ppm}} 50.1,109.8,121.7,151.0,167.3 ; \mathrm{MS}: \mathrm{m} / \mathrm{z}=338[\mathrm{M}]^{+}$.

General procedure for the tandem Knoevenagel-Michael cyclocondensation reaction synthesis of tetrahydrobenzo[b]pyran derivatives

$\left\{\left[4,4^{\prime}-\mathrm{BPyH}\right]\left[\mathrm{C}(\mathrm{CN})_{3}\right]_{2}\right\}(1 \mathrm{~mol} \% ; 0.0034 \mathrm{~g})$ as a green mild catalyst was added to a mixture of aromatic aldehydes $(1 \mathrm{mmol})$, malononitrile $(0.066 \mathrm{~g}, 1 \mathrm{mmol})$ and dimedone $(0.140 \mathrm{~g}, 1 \mathrm{mmol})$ in a round bottom flask, and the consequent mixture was first stirred magnetically under solvent-free condition at room temperature. After completion of the reaction, as known by TLC $n$-hexane/ethyl acetate (5:2), ethyl acetate $(10 \mathrm{~mL})$ was added to the reaction mixture, stirred and refluxed for $5 \mathrm{~min}$, and then was washed with water $(10 \mathrm{~mL})$ and decanted to separate catalyst from the reaction mixture (the reaction mixture was soluble in hot ethyl acetate and NMS catalyst was soluble in water). The solvent of organic layer was evaporated and the crude product was purified via recrystallization from ethanol/water (10:1). In this investigation, bifunctional NMS catalyst was recycled and reused for four experimental errors with negligible losing of its catalytic activity.

General procedure for the synthesis of amido or aminoalkyl naphthol derivatives

$\left\{\left[4,4^{\prime}-\mathrm{BPyH}\right]\left[\mathrm{C}(\mathrm{CN})_{3}\right]_{2}\right\}(1 \mathrm{~mol} \% ; 0.0034 \mathrm{~g})$ as a green mild catalyst was added to a mixture of aromatic aldehydes $(1 \mathrm{mmol}), \beta$-naphthol $(0.144 \mathrm{~g}, 1 \mathrm{mmol})$ and amide or amine derivatives $(1 \mathrm{mmol})$ in a round bottom flask, and the subsequent mixture was first stirred magnetically under solvent-free 
condition at $75{ }^{\circ} \mathrm{C}$. After completion of the reaction, as identified by TLC $n$-hexane/ethyl acetate (5:3), ethyl acetate $(10 \mathrm{~mL})$ was added to a reaction mixture, stirred and refluxed for $5 \mathrm{~min}$, and then was washed with water $(10 \mathrm{~mL})$ and decanted to separate catalyst from the reaction mixture (the reaction mixture was soluble in hot ethyl acetate and NMS catalyst was soluble in water). The solvent of organic layer was evaporated and the crude product was purified by recrystallization from ethanol/water (10:1). In this study, bifunctional NMS catalyst were recycled and reused for five experimental errors with a minor loss of its catalytic activity.

Spectral data analysis for compounds

2-Amino-4-(4-fluorophenyl)-7,7-dimethyl-5-oxo-5,6,7,8-tetrahydro-4H-chromene-3-carbonitrile

(Table 3, entry 8)

White solid; M.p: 188-190 ${ }^{\circ} \mathrm{C}$; Yield: $96 \%$; IR (KBr): $v_{\max }=3358,3181,2900,2190,1673,1637$, 1507, 1366, $1216 \mathrm{~cm}^{-1} ;{ }^{1} \mathrm{H}$ NMR $\left(400 \mathrm{MHz}, \mathrm{DMSO}-d_{6}\right): \delta_{\mathrm{ppm}}=0.95\left(\mathrm{~s}, 3 \mathrm{H}-\mathrm{CH}_{3}\right), 1.04\left(\mathrm{~s}, 3 \mathrm{H},-\mathrm{CH}_{3}\right)$, $2.13\left(\mathrm{~d}, 2 \mathrm{H}, J=8.0 \mathrm{~Hz},-\mathrm{CH}_{2}\right), 2.27\left(\mathrm{~d}, 2 \mathrm{H}, J=8.0 \mathrm{~Hz},-\mathrm{CH}_{2}\right), 4.20$ (s, 1H, $-\mathrm{CH}$ aliphatic), 7.11 (s, $\left.2 \mathrm{H},-\mathrm{NH}_{2}\right), 7.16(\mathrm{~d}, 2 \mathrm{H}, J=6.0 \mathrm{~Hz}, \mathrm{ArH}), 7.20(\mathrm{~d}, 2 \mathrm{H}, J=6.0 \mathrm{~Hz}, \mathrm{ArH}) ;{ }^{13} \mathrm{C}$ NMR $(100 \mathrm{MHz}, \mathrm{DMSO}-$ $\left.d_{6}\right): \delta_{\mathrm{ppm}}=26.8,28.3,31.8,34.8,49.9,58.0,112.6,114.9,115.1,119.6,129.0,129.1,158.3,158.4,159.7$, $162.1,162.5,195.7$.

2-Amino-4-(4-bromophenyl)-7,7-dimethyl-5-oxo-5,6,7,8-tetrahydro-4H-chromene-3-carbonitrile (Table 3, entry 14)

White solid; M.p: 205-207 ${ }^{\circ} \mathrm{C}$; Yield: 92\%; IR (KBr): $v_{\max }=3319,3183,2962,2169,1682,1655$, 1367, $1215 \mathrm{~cm}^{-1} ;{ }^{1} \mathrm{H}$ NMR (400 MHz, DMSO- $\left.d_{6}\right): \delta_{\mathrm{ppm}}=0.95\left(\mathrm{~s}, 3 \mathrm{H}-\mathrm{CH}_{3}\right), 1.04\left(\mathrm{~s}, 3 \mathrm{H},-\mathrm{CH}_{3}\right), 2.13(\mathrm{~d}$, $\left.2 \mathrm{H}, J=8.0 \mathrm{~Hz},-\mathrm{CH}_{2}\right), 2.27\left(\mathrm{~d}, 2 \mathrm{H}, J=8.0 \mathrm{~Hz},-\mathrm{CH}_{2}\right), 3.36\left(\mathrm{~s}, 2 \mathrm{H},-\mathrm{NH}_{2}\right), 4.18(\mathrm{~s}, 1 \mathrm{H},-\mathrm{CH}$ aliphatic), $7.13(\mathrm{~d}, 2 \mathrm{H}, J=8.4 \mathrm{~Hz}, \mathrm{ArH}), 7.50(\mathrm{~d}, 2 \mathrm{H}, J=8.4 \mathrm{~Hz}, \mathrm{ArH}) ;{ }^{13} \mathrm{C}$ NMR $\left(100 \mathrm{MHz}, \mathrm{DMSO}-d_{6}\right)$ : $\delta_{\mathrm{ppm}}=18.5,26.8,28.3,31.8,35.1,49.9,55.9,57.6,112.2,119.5,119.6,129.5,131.2,144.1,158.3,158.4$, 162.6, 195.7.

4,4'-(1,4-Phenylene)bis(2-amino-7,7-dimethyl-5-oxo-5,6,7,8-tetrahydro-4H-chromene-3carbonitrile) (Table 3, entry 15)

White solid; M.p: $269-271{ }^{\circ} \mathrm{C}$; Yield: 85\%; IR (KBr): $v_{\max }=3452,3331,3187,2962,2198,1683$, 1665, 1364, $1212 \mathrm{~cm}^{-1} ;{ }^{1} \mathrm{H}$ NMR $\left(400 \mathrm{MHz}, \mathrm{DMSO}-d_{6}\right): \delta_{\mathrm{ppm}}=0.99\left(\mathrm{~s}, 6 \mathrm{H}-\mathrm{CH}_{3}\right), 1.04\left(\mathrm{~s}, 6 \mathrm{H},-\mathrm{CH}_{3}\right)$, $2.19\left(\mathrm{~d}, 4 \mathrm{H}, J=8.0 \mathrm{~Hz},-\mathrm{CH}_{2}\right), 2.26\left(\mathrm{~d}, 4 \mathrm{H}, J=8.0 \mathrm{~Hz},-\mathrm{CH}_{2}\right), 2.51\left(\mathrm{~s}, 4 \mathrm{H},-\mathrm{NH}_{2}\right), 4.14(\mathrm{~s}, 2 \mathrm{H},-\mathrm{CH}$ aliphatic), 7.04 (s, 4H, ArH); ${ }^{13} \mathrm{C}$ NMR (100 MHz, DMSO- $\left.d_{6}\right): \delta_{\mathrm{ppm}}=27.2,28.2,31.8,34.9,49.9,58.3$, $112.7,112.8,119.7,126.9,142.8,158.4,158.5,162.7,195.8$.

2-Amino-4-(3-chlorophenyl)-7,7-dimethyl-5-oxo-5,6,7,8-tetrahydro-4H-chromene-3-carbonitrile (Table 3, entry 17) 
White solid; M.p: 230-232 ${ }^{\circ} \mathrm{C}$; Yield: 94\%; IR (KBr): $v_{\max }=3321,3184,2965,2191,1682,1659$, 1372, $1213 \mathrm{~cm}^{-1} ;{ }^{1} \mathrm{H}$ NMR $\left(400 \mathrm{MHz}, \mathrm{DMSO}-d_{6}\right): \delta_{\mathrm{ppm}}=0.96\left(\mathrm{~s}, 3 \mathrm{H}-\mathrm{CH}_{3}\right), 1.04\left(\mathrm{~s}, 3 \mathrm{H},-\mathrm{CH}_{3}\right), 2.15(\mathrm{~d}$, $\left.2 \mathrm{H}, J=8.0 \mathrm{~Hz},-\mathrm{CH}_{2}\right), 2.28\left(\mathrm{~d}, 2 \mathrm{H}, J=8.4 \mathrm{~Hz},-\mathrm{CH}_{2}\right), 2.53\left(\mathrm{~s}, 2 \mathrm{H},-\mathrm{NH}_{2}\right), 4.22(\mathrm{~s}, 1 \mathrm{H},-\mathrm{CH}$ aliphatic), $7.13(\mathrm{~d}, 1 \mathrm{H}, J=7.6 \mathrm{~Hz}, \mathrm{ArH}), 7.17$ (s, 1H, ArH), 7.27 (d, 1H, $J=8.0 \mathrm{~Hz}, \mathrm{ArH}), 7.36$ (t, 1H, $=7.6 \mathrm{~Hz}, \mathrm{ArH}) ;{ }^{13} \mathrm{C}$ NMR $\left(100 \mathrm{MHz}, \mathrm{DMSO}-d_{6}\right): \delta_{\mathrm{ppm}}=26.8,28.2,31.8,35.3,49.9,57.6,112.0,119.4$, $125.9,126.6,127.0,130.3,132.9,147.2,158.4,158.5,162.8,195.7$.

\section{Results and discussion}

Application of [4,4'-bipyridine]-1,1'-diium tricyanomethanide $\left\{\left[4,4^{\prime}-\mathrm{BPyH}\right]\left[\mathrm{C}(\mathrm{CN})_{3}\right]_{2}\right\}$ as a bifunctional nano structure molten salt catalyst in the synthesis of tandem Knoevenagel-Michael cyclocondensation synthesis of tetrahydrobenzo[b]pyran derivatives.

Firstly, to optimize the reaction conditions, the condensation reaction of 4-chlorobenzaldehyde, malononitrile and dimedone was chosen as a typical model and various amounts of bifunctional nano structure molten salt catalyst at range of $25-100{ }^{\circ} \mathrm{C}$ were tested under solvent-free conditions (Table 1). As revealed in Table 1, the best results were attained when the reaction was achieved in the presence of 1 mol\% of bifunctional nano structure molten salt at room temperature (Table 1, entries 5 and 9). No improvement was identified in the yield of reaction via increasing the amount of the nano molten salt catalyst and the temperature. Table 1 clearly displays that in the absence of nano molten salt catalyst, reaction progressed slowly and the product was obtained with low yield (Table 1, entries 1 and 2).

$>$ Table $1<$

To compare the effect of the solution with solvent-free conditions, a mixture of 4chlorobenzaldehyde, malononitrile and dimedone was selected as classic reaction, by 1 mol\% of bifunctional nano structure molten salt as a catalyst in numerous solvents for instance $\mathrm{H}_{2} \mathrm{O}, \mathrm{CH}_{3} \mathrm{CN}$, $\mathrm{C}_{2} \mathrm{H}_{5} \mathrm{OH}, \mathrm{CH}_{2} \mathrm{Cl}_{2}, \mathrm{CH}_{3} \mathrm{CO}_{2} \mathrm{Et}, n$-hexane and toluene was studied at room temperature. As it can be detected in Table 2, solvent-free condition was the best one in this reaction. Consequently, solvent-free condition was selected for running condensation reactions.

$>$ Table $2<$

After optimization of the reaction conditions, to consider the efficacy and the scope of the presented procedure, various of tetrahydrobenzo[b]pyran derivatives were prepared by the one-pot threecomponent tandem Knoevenagel-Michael cyclocondensation reaction between aromatic aldehydes, malononitrile and dimedone in the presence of a catalytic amount of [4,4'-bipyridine]-1,1'-diium tricyanomethanide $\left\{\left[4,4^{\prime}-\mathrm{BPyH}\right]\left[\mathrm{C}(\mathrm{CN})_{3}\right]_{2}\right\}$ as a novel bifunctional nano structure molten salt catalyst at 
room temperature under solvent-free reaction conditions. The results are presented in Table 3. The effect of substituents on the aromatic ring displayed was estimated strong in terms of yields under same reaction conditions. All aromatic aldehydes including electron-releasing substituents and electron-withdrawing substituents on their aromatic ring provided the desired products in high to excellent yields in short reaction times. The reaction times of aromatic aldehydes possessing electron withdrawing groups were rather faster than electron donating groups.

\section{$>$ Table $3<$}

A plausible mechanism for the creation of the tetrahydrobenzo[b]pyran (4) is well-defined in Scheme 3 [16a]. Firstly, $\left\{\left[4,4^{\prime}-\mathrm{BPyH}\right]\left[\mathrm{C}(\mathrm{CN})_{3}\right]_{2}\right\}$ as a nano molten salt (NMS) catalyst activates the carbonyl group of the aromatic aldehyde to provide intermediate (8) and malononitrile (2) tautomerized to (9). The tandem Knoevenagel condensation of intermediate (8) and (9) was happened to form the arylidene malononitrile (11). Subsequently, dimedone (3) tautomerized to (10) tolerates nucleophilic attack to (11) and affords the Michael adduct (12). The Michael adduct (12) tautomerizes using NMS catalyst to make intermediate (13) which cyclizes to provide compound (14) and which then tautomerized to afford the completely aromatized tetrahydrobenzo[b]pyran (4).

$>$ Scheme $3<$

Furthermore, reusability of the $\left\{\left[4,4^{\prime}-\mathrm{BPyH}\right]\left[\mathrm{C}(\mathrm{CN})_{3}\right]_{2}\right\}$ as a bifunctional NMS catalyst was approved via condensation of 4-chlorobenzaldehyde, malononitrile and dimedone as a model. At the end of the reaction, ethyl acetate was added to the reaction mixture and heated to extract product from remained substances. This solution was washed with water to separate bifunctional NMS catalyst from other materials (the product is soluble in hot ethyl acetate and bifunctional NMS catalyst is soluble in water). The aqueous layer was decanted, separated and used for additional reaction after eliminating water. It is identified that the catalytic activity of the catalyst was restored within the limits of the experimental errors for four continuous runs (Table 4). The deactivation of the bifunctional NMS catalyst is low. The reaction was scaled up to $10 \mathrm{mmol}$ of 4-chlorobenzaldehyde, malononitrile and dimedone by $10 \mathrm{~mol} \%$ of $\left\{\left[4,4^{\prime}-\mathrm{BPyH}\right]\left[\mathrm{C}(\mathrm{CN})_{3}\right]_{2}\right\}$ as a bifunctional NMS catalyst at room temperature. The yield of the reaction was $94 \%$ after $7 \mathrm{~min}$ and $78 \%$ after $12 \mathrm{~min}$ the fourth run.

$>$ Table $4<$

Application of [4,4'-bipyridine]-1,1'-diium tricyanomethanide $\left\{\left[4,4^{\prime}-\mathrm{BPyH}\right]\left[\mathrm{C}(\mathrm{CN})_{3}\right]_{2}\right\}$ as a bifunctional nano structure molten salt catalyst in the synthesis of amido or aminoalkyl naphthol derivatives. 
After the synthesis of $\left\{[4,4\right.$ '- $\left.\mathrm{BPyH}]\left[\mathrm{C}(\mathrm{CN})_{3}\right]_{2}\right\}$ as a bifunctional nano structure molten salt catalyst, to optimize the reaction conditions, we approved the effect of the NMS catalyst in the synthesis of amino or amidoalkyl naphthols (Scheme 2). For this purpose, as a typical reaction, the condensation between acetamide, 4-chlorobenzaldehyde and $\beta$-naphthol was studied using different amounts of the catalyst at range of $25-125{ }^{\circ} \mathrm{C}$ under solvent-free conditions (Table 5). As Table 5 displays, the best results were attained when the reaction was achieved in the presence of $1 \mathrm{~mol} \%$ of NMS catalyst at $75{ }^{\circ} \mathrm{C}$ (Table 5, entry 7). Increasing the reaction temperature and catalyst loading did not improve the rate of the reaction (Table 5, entries 9-13). In the absence of catalyst a low yield of the products was attained after $120 \mathrm{~min}$ (Table 5, entries 1 and 2).

\section{$>$ Table $5<$}

To compare the result of the solution with that of solvent-free conditions, a mixture of acetamide, 4-chlorobenzaldehyde and $\beta$-naphthol as a model reaction, using $1 \mathrm{~mol} \%$ of NMS catalyst in numerous solvents such as $\mathrm{H}_{2} \mathrm{O}, \mathrm{C}_{2} \mathrm{H}_{5} \mathrm{OH}, \mathrm{CH}_{3} \mathrm{CN}, \mathrm{CH}_{3} \mathrm{CO}_{2} \mathrm{Et}, \mathrm{CH}_{2} \mathrm{Cl}_{2}, n$-Hexane and toluene was investigated under reflux conditions. Also, reaction was performed under solvent-free condition at $75{ }^{\circ} \mathrm{C}$. As it can be seen in Table 6, solvent-free condition was the best one in this reaction.

$>$ Table $6<$

With the purpose of approving this main process, we decided to synthesize several amido or aminoalkyl naphthol derivatives from three-component condensation reaction of numerous aromatic aldehyde, $\beta$-naphthol and several amine or amide under solvent-free conditions at $75{ }^{\circ} \mathrm{C}$ in the presence of a catalytic amount of $\left\{\left[4,4^{\prime}-\mathrm{BPyH}\right]\left[\mathrm{C}(\mathrm{CN})_{3}\right]_{2}\right\}$ as a NMS catalyst. The results are presented in Table 7. The effect of substituents on the aromatic ring exhibitions was estimated strong in terms of yields under these reaction conditions. All aromatic aldehydes bearing electron-withdrawing and electron-releasing substituents on their aromatic ring provided the related products in high to excellent yields in short reaction time. The reaction time of aromatic aldehydes having electron-withdrawing groups was rather faster than that of electron donating groups.

$>$ Table $7<$

In Scheme 4, we have proposed a probable mechanism for the synthesis of amido or aminoalkyl naphthol derivatives using $\left\{\left[4,4^{\prime}-\mathrm{BPyH}\right]\left[\mathrm{C}(\mathrm{CN})_{3}\right]_{2}\right\}$ as a NMS catalyst. The reaction of aromatic aldehydes with $\beta$-naphthol in the presence of NMS catalyst is plausible to produce ortho-quinone methides (o-QMs). The prepared $\boldsymbol{o}$-QMs, reacted with amide or amine derivatives to provide amido or aminoalkyl naphthols. A practical explanation for this result can be identified by studying the 
nucleophilic addition of amide or amine to $\mathbf{0 - Q M s}$ intermediate and eventually the desired product was attained after aromatization $[25,26]$.

$>$ Scheme $4<$

Furthermore, recyclability and reusability of the $\left\{\left[4,4^{\prime}-\mathrm{BPyH}\right]\left[\mathrm{C}(\mathrm{CN})_{3}\right]_{2}\right\}$ as a NMS catalyst was approved from the condensation between acetamide, 4-chlorobenzaldehyde and $\beta$-naphthol. After the completion of the reaction, ethyl acetate was added to the reaction mixture and heated to extract the product. This solution was washed with water to separate catalyst from other materials (the product is soluble in hot ethyl acetate and NMS catalyst is soluble in water). The aqueous layer was decanted, separated and used for alternative reaction after removing of water. It has been proved that the catalytic activity of the catalyst was changed within the limits of the experimental errors for five continuous runs. The deactivation of the NMS catalyst is low. The reaction was scaled up to $10 \mathrm{mmol}$ of acetamide, 4chlorobenzaldehyde and $\beta$-naphthol using $10 \mathrm{~mol} \%$ of NMS catalyst at $75{ }^{\circ} \mathrm{C}$. The yield of the reaction was $93 \%$ after 20 min and $91 \%$ after the fifth run. The results are summarized in Fig. 1.

$>$ Fig. $1<$

\section{Conclusion}

In summary, an environmentally friendly, green, mild and efficient bifunctional nano structure molten salt catalyst namely $[4,4$ '-bipyridine $]-1,1^{\prime}$-diium tricyanomethanide $\left\{[4,4\right.$ '- $\left.\mathrm{BPyH}]\left[\mathrm{C}(\mathrm{CN})_{3}\right]_{2}\right\}$ was used and investigated in the synthesis of tandem Knoevenagel-Michael cyclocondensation synthesis of tetrahydrobenzo[b]pyran derivatives by three-component condensation reaction of various aldehydes, malononitrile and dimedone under solvent-free conditions at room temperature. In another study catalytic properties of $\left\{\left[4,4^{\prime}-\mathrm{BPyH}\right]\left[\mathrm{C}(\mathrm{CN})_{3}\right]_{2}\right\}$, it was applied in the synthesis of amido and aminoalkyl naphthol derivatives under solvent-free conditions at $75{ }^{\circ} \mathrm{C}$. Other works offered that the NMS basicity and acidity displays a significant role to play in the dual-catalyzed reactions. Different noteworthy advantages of this study are reasonably ease of product isolation, cleaner reaction profile, short reaction time, high yield, recyclability of the NMS catalyst and accordance with the green chemistry disciplines. More study for systematic and knowledge-based development of nano molten salt is going on in our research group.

\section{Acknowledgement}

We thank Bu-Ali Sina University, Iran National Science Foundation (INSF) (The Grant of Allameh Tabataba'i's Award, Grant Number BN093) and National Elites Foundation for financial support to our research group. 
Appendix A. Supplementary data

Supplementary data to this article can be found online at http://dx.doi.org.10.1016/j.molliq.2016.xx.xxx.

\section{References}

[1] M.B. Gawande, P.S. Branco, An efficient and expeditious Fmoc protection of amines and amino acids in aqueous media, Green Chem., 13 (2011) 3355-3359.

[2] (a) T. Welton, Room-temperature ionic liquids. Solvents for synthesis and catalysis, Chem. Rev., 99 (1999) 2071-2084; (b) K.R. Seddon, A. Stark, M. Torres, Influence of chloride, water, and organic solvents on the physical properties of ionic liquids, J. Pure Appl. Chem., 72 (2000) 22752287; (c) J. Dupont, R.F. De Souza, P.A.Z. Suarez, Ionic liquid (molten salt) phase organometallic catalysis, Chem. Rev., 102 (2002) 3667-3692.

[3] P. Wasserscheid, W. Keim, Ionic liquids - new "solutions" for transition metal catalysis, Angew. Chem. Int. Ed., 39 (2000) 3772-3789.

[4] J.R. Mac Callum, C.A. Vincent, (Eds.), "Polymer electrolytes reviews", Elsevier, London, vol. 1 (1987).

[5] J.R. Mac Callum, C.A. Vincent, (Eds.), "Polymer electrolytes reviews", Elsevier, London, vol. 2 (1989).

[6] P.A. Madden, M. Wilson, 'Covalent' effects inionic 'liquids', J. Phys. Condens. Matter., 12 (2000) A95-A108.

[7] L.J.A. Siqueira, S. Urahata, M.C.C. Ribeiro, Molecular dynamics simulation of molten sodium chlorate, J. Chem. Phys., 119 (2003) 8002-8012.

[8] N. Gokon, Y. Oku, H. Kaneko, Y. Tamaura, Methane reforming with $\mathrm{CO}_{2}$ in molten salt using FeO catalyst, Solar Energy., 72 (2002) 243-250.

[9] M. Kusche, F. Agel, N.N. Bhriain, A. Kaftan, M. Laurin, J. Libuda, P. Wasserscheid, Methanol steam reforming promoted by molten salt-modified platinum on alumina catalysts, Chem. Sus. Chem., 7 (2014) 2516-2526.

[10] (a) M.C. Wani, H.L. Taylor, M.E. Wall, Plant antitumour agents: colubrinol acetate and colubrinol, antileukaemic ansa macrolides from Colubrina texensis, J. Chem. Soc., Chem. Commun., 1973, 390-390.; (b) R.C. Cioc, E. Ruijter, R.V.A. Orru, Multicomponent reactions: advanced tools for sustainable organic symthesis, Green Chem., 16 (2014) 2958-2975. 
[11] (a) A. Alizadeh, F. Mobahedi, A. Esmaili, A new method for the synthesis of functionalized maleimides, Tetrahedron Lett., 47 (2006) 4469-4471.; (b) C. Liu, L. Zhou, D. Jiang, Y. Gu, Multicomponent reactions of aldo-X bifunctional reagent $\alpha$-oxoketene dithioacetals and indols or amines: divergent synthesis of dihydrocoumarins, quinolines, furans and pyrroles, Asian J. Org. Chem. 5 (2016) 367-372. (c) A. Mondal, C. Mukhopadhyay, $\mathrm{FeCl}_{3}$-catalyzed combinatorial synthesis of functionalized spiro[indolo-3,10'-indeno [1,2-b]quinolin]-trione derivatives, ACS Comb. Sci., 17 (2015) 404-408.

[12] L. Weber, K. Illegen, M. Almstetter, Discovery of new multi component reactions with combinatorial methods, Synlett, (1999) 366-374.

[13] G.R. Green, J.M. Evans, A.K. Vong, "In Comprehensive Heterocyclic Chemistry II", A.R. Katritzky, C.W. Rees, E.F.V. Scriven, Eds., Pergamon Press, Oxford, Vol. 5 (1995) 469.

[14] (a) W.O. Foye, "Prinicipi di Chemico Farmaceutica", Piccin, Padova, Italy, (1991) 416; (b) A.L. Lazzeri, E. Lapi, On some new esters of coumarin-3-carboxylic acid with balsamic and bronchodilator action, Bull. Chim. Farm., 99 (1960) 583-586; (c) L. Bonsignore, G. Loy, D. Secci, A. Calignano, Synthesis and pharmacological activity of 2-oxo-(2H)1-benzopyran-3carboxamide derivatives, Eur. J. Med. Chem., 28 (1993) 517-520.

[15] C.S. Konkoy, D.B. Fick, S.X. Cai, N.C. Lan, J.F.W. Keana, PCT Int. Appl. WO. Patent 0075123 (2000); Chem. Abstr., 134 (2001) 29313a.

[16] (a) A. Khazaei, F. Gholami, V. Khakyzadeh, A.R. Moosavi-Zare, J. Afsar, Magnetic core-shell titanium dioxide nanoparticles as an efficient catalyst for domino Knoevenagel-Michaelcyclocondensation reaction of malononitrile, various aldehydes and dimedone, RSC. Adv., 5 (2015) 14305-14310; (b) D. Fang, H.B. Zhang, Z.L. Liu, Synthesis of 4H-benzopyrans catalyzed by acyclic acidic ionic liquids in aqueous media, J. Heterocycl. Chem., 47 (2010) 63-67; (c) D.M. Pore, K.A. Undale, B.B. Dongare, U.V. Desai, Potassium phosphate catalyzed a rapid threecomponent synthesis of tetrahydrobenzo[b]pyran at ambient temperature, Catal. Lett., 132 (2009) 104-108; (d) L.Q. Yu, F. Liu, Q.D. You, One-pot synthesis of tetrahydrobenzo[b]pyran derivatives catalyzed by amines in aqueous media, Org. Prep. Proced. Int., 41 (2009) 77-82; (e) G. Sabitha, K. Arundhathi, K. Sudhakar, B.S. Sastry, J.S. Yadav, Cerium(III)chloride-catalyzed one-pot synthesis of tetrahydrobenzo[b]pyrans, Synth. Commun., 39 (2009) 433-442; (f) R. Hekmatshoar, S. Mojedi, Kh. Bakhtiari, Sodium selenate catalyzed simple and efficient synthesis of tetrahydro benzo [b] pyran derivatives, Catal. Commun., 9 (2008) 307-310; (g) X.Z. Lian, Y. Huang, Y.Q. Li, W.J. Zheng, A green synthesis of tetrahydrobenzo[b]pyran derivatives through three-component condensation using $\mathrm{N}$-methylimidazole as organocatalyst, Monatsh. Chem., 139 
(2008) 129-131; (h) S. Balalaie, M. Bararjanian, M. Sheikh-Ahmadi, S. Hekmat, P. Salehi, Diammonium hydrogen phosphate: an efficient and versatile catalyst for the one-pot synthesis of tetrahydrobenzo[b]pyran derivatives in aqueous media, Synth. Commun., 37 (2007) 1097-1108; (i) S. Balalaie, M. Bararjanian, A.M. Amani, B. Movassagh, Lithium bromide as a mild, efficient, and recyclable catalyst for the one-pot synthesis of tetrahydro- $4 \mathrm{H}$-chromene derivatives in aqueous media, Synlett, (2006) 263-266; (j) J.T. Li, W.Z. Xu, L.C. Yang, T.S. Li, One-pot synthesis of 2-amino-4-aryl-3-carbalkoxy-7,7-dimethyl-5,6,7,8-tetrahydrobenzo[b]pyran derivatives catalyzed by $\mathrm{KF} / \mathrm{Basic} \mathrm{Al}_{2} \mathrm{O}_{3}$ under ultrasound irradiation, Synth. Commun., 34 (2004) 4565-4571; (k) X.S. Wang, D.Q. Shi, S.T. Tu, C.S. Yao, Synth. Commun., 33 (2003) 119; (l) T.S. Jin, A.Q. Wang, X. Wang, J.S. Zhang, T.S. Li, A clean one-pot synthesis of tetrahydrobenzo[b]pyran derivatives catalyzed by hexadecyltrimethyl ammonium bromide in aqueous media , Synlett, (2004) 871-873; (m) L. Fotouhi, M.M. Heravi, A. Fatehi, K. Bakhtiari, Electrogenerated base-promoted synthesis of tetrahydrobenzo[b]pyran derivatives, Tetrahedron Lett., 48 (2007) 5379-5381; (n) S. Balalaie, M. Sheikh-Ahmadi, M. Bararjanian, Tetra-methyl ammonium hydroxide: an efficient and versatile catalyst for the one-pot synthesis of tetrahydrobenzo[b]pyran derivatives in aqueous media, Catal. Commun., 8 (2007) 1724-1728; (o) Y.Q. Peng, G.H. Song, Amino-functionalized ionic liquid as catalytically active solvent for microwave-assisted synthesis of 4H-pyrans, Catal. Commun., 8 (2007) 111-114; (p) S. Gurumurthi, V. Sundari, R. Valliappan, An efficient and convenient approach to synthesis of tetrahydrobenzo[b]pyran derivatives using tetrabutylammonium bromide as catalyst, E-J. Chem., 6 (2009) S466-S472.

[17] C. Cardellicchio, M.A.M. Capozzi, F. Naso, The Betti base: the awakening of a sleeping beauty, Tetrahedron Asymm., 21 (2010) 507-517.

[18] (a) M. Betti, General condensation reaction between $\beta$-naphthol, aldehydes and amines, Gazz. Chim. Ital., 30 (1900) 310-316; (b) M. Betti, $\beta$-Naphthol phenylaminomethane, Org. Synth. Coll., 1 (1941) 381-383; (c) M.R. Saidi, N. Azizi, M.R. Naimi-Jamal, Lithium perchlorate assisted onepot three-component aminoalkylation of electron-rich aromatic compounds, Tetrahedron Lett., 42 (2001) 8111-8113; (d) A. Jha, K. N. Paul, S. Trikha, T.S. Cameron, Novel synthesis of 2naphthol Mannich bases and their NMR behaviour, Can. J. Chem., 84 (2006) 843-853.

[19] L. Jun, X. Xuenong, C. Wang, H. Jiangang, H. Yuefei, Synthesis of chiral ligands derived from the Betti base and their use in the enantioselective addition of diethyl zinc to aromatic aldehydes, Tetrahedron Lett., 43 (2002) 8367-8369. 
[20] A.Y. Shen, C.T. Tsai, C.L. Chen, Synthesis and cardiovascular evaluation of N-substituted 1aminomethyl-2-naphthols, Eur. J. Med. Chem., 34 (1999) 877-882.

[21] (a) I. Szatmari, A. Hetenyi, L. Lazar, F. Fulop, Transformation reactions of the Betti base analog aminonaphthols, J. Heterocycl. Chem., 41 (2004) 367-373; (b) M. Heydenreich, A. Koch, S. Klod, I. Szatmari, F. Fulop, E. Kleinpeter, Synthesis and conformational analysis of naphth[1',2':5,6][1,3] oxazino[3,2-c][1,3]benzoxazine and naphth $\left[1^{\prime}, 2^{\prime}: 5,6\right][1,3]$ oxazino[3,4c][1,3]benzoxazine derivatives, Tetrahedron, 62 (2006) 11081-11089.

[22] A. Zare, H. Kaveh, M. Merajoddin, A.R. Moosavi-Zare, A. Hasaninejad, M.A. Zolfigol, Saccharin Ssulfonic acid (SASA) as a highly efficient catalyst for the condensation of 2-naphthol with arylaldehydes and amides (thioamides or alkyl carbamates) under green, mild, and solventfree conditions, Phos. Sulf. Silicon and Rel. Elements., 188 (2013) 573-584.

[23] V.K. Das, M. Borah, A.J. Thakur, Piper-Betle-Shaped nano-S-catalyzed synthesis of 1amidoalkyl-2-naphthols under solvent-free reaction condition: a greener "nanoparticle-catalyzed organic synthesis enhancement" approach, J. Org. Chem., 78 (2013) 3361-3366.

[24] M.A. Zolfigol, A. Khazaei, A.R. Moosavi-Zare, A. Zare, V. Khakyzadeh, Rapid synthesis of 1amidoalkyl-2-naphthols over sulfonic acid functionalized imidazolium salts, Appl. Catal. A: Gen., 400 (2011) 70-81.

[25] M.A. Zolfigol, S. Baghery, A.R. Moosavi-Zare, S.M. Vahdat, H. Alinezhad, M. Norouzi, Design of 1-methylimidazolium tricyanomethanide as the first nanostructured molten salt and its catalytic application in the condensation reaction of various aromatic aldehydes, amides and $\beta$-naphthol compared with tin dioxide nanoparticles, RSC Adv., 5 (2015) 45027-45037.

[26] M.A. Zolfigol, S. Baghery, A.R. Moosavi-Zare, S.M. Vahdat, Synthesis and characterization of new 1-( $\alpha$-aminoalkyl)-2-naphthols using pyrazine-1,4-diium trinitromethanide $\{[1,4-$ DHPyrazine $\left.]\left[\mathrm{C}\left(\mathrm{NO}_{2}\right)_{3}\right]_{2}\right\}$ as a novel nano-structured molten salt and catalyst in compared with Ag- $\mathrm{TiO}_{2}$ nano composite, J. Mol. Catal. A: Chem., 409 (2015) 216-226.

[27] M. Ghandi, A. Olyaei, S. Raoufmoghaddam, One-pot, three-component uncatalyzed quantitative synthesis of new aminonaphthols (Betti bases) in water, Synth. Commun., 38 (2008) 4125-4138.

[28] H. Moghanian, A. Mobinikhaledi, A.G. Blackmanc, E. Sarough-Farahani, Sulfanilic acidfunctionalized silica-coated magnetite nanoparticles as an efficient, reusable and magnetically separable catalyst for the solvent-free synthesis of 1-amido- and 1-aminoalkyl-2-naphthols , RSC Adv., 4 (2014) 28176-28185.

[29] See our reviews: (a) P. Salehi, M.A. Zolfigol, F. Shirini, M. Baghbanzadeh, Silica sulfuric acid and silica chloride as efficient reagents for organic reactions, Curr. Org. Chem., 10 (2006) 2171- 
2189; (b) F. Shirini, M.A. Zolfigol, P. Salehi, M. Abedini, Applications of some metal hydrogen sulfates in organic transformations, Curr. Org. Chem., 12 (2008) 183-202; (c) M. Daraei, M.A. Zolfigol, F. Derakhshan-Panah, M. Shiri, H.G. Kruger, M. Mokhlesi, Synthesis of tetrahydropyridines by one-pot multicomponent reaction using nano-sphere silica sulfuric acid, J. Iran. Chem. Soc., 12 (2015) 855-861; (d) D. Azarifar, S.M. Khatami, M.A. Zolfigol, R. NejatYami, Nano-titania sulfuric acid-promoted synthesis of tetrahydrobenzo[b]pyran and 1, 4dihydropyrano[2,3-c]pyrazole derivatives under ultrasound irradiation, J. Iran. Chem. Soc., 11 (2014) 1223-1230; (e) M. Safaiee, M.A. Zolfigol, M. Tavasoli, M. Mokhlesi, Application of silica vanadic acid $\left[\mathrm{SiO}_{2}-\mathrm{VO}(\mathrm{OH})_{2}\right]$ as a heterogeneous and recyclable catalyst for oxidative aromatization of Hantzsch 1,4-dihydropyridines at room temperature, J. Iran. Chem. Soc., 11 (2014) 1593-1597; (f) M.A. Zolfigol, R. Ayazi, S. Baghery, Synthesis and characterization of two novel biological-based nano organo solid acids with urea moiety and their catalytic applications in the synthesis of 4,4'-(arylmethylene)bis(1H-pyrazol-5-ol), coumarin-3-carboxylic acid and cinnamic acid derivatives under mild and green conditions, RSC Adv., 5 (2015) 71942-71954.

[30] (a) A. R. Moosavi-Zare, M.A. Zolfigol, V. Khakyzadeh, C. Böttcher, M.H. Beyzavi, A. Zare, A. Hasaninejad, R. Luque, Facile preparation of a nanostructured functionalized catalytically active organosalt, J. Mater. Chem. A., 2 (2014) 770-777; (b) M.A. Zolfigol, S. Baghery, A.R. MoosaviZare, S.M. Vahdat, Synthesis of 1,2,4,5-tetrasubstituted imidazoles using 2,6-dimethylpyridinium trinitromethanide $\left\{[2,6-\mathrm{DMPyH}] \mathrm{C}\left(\mathrm{NO}_{2}\right)_{3}\right\}$ as a novel nanostructured molten salt and green catalyst, RSC Adv., 5 (2015) 32933-32940; (c) M.A. Zolfigol, S. Baghery, A.R. Moosavi-Zare, S.M. Vahdat, H. Alinezhad, M. Norouzi, Synthesis of the first nano ionic liquid 1methylimidazolium trinitromethanide $\left\{[\mathrm{HMIM}] \mathrm{C}\left(\mathrm{NO}_{2}\right)_{3}\right\}$ and its catalytic use for Hanztsch four-component condensation, RSC. Adv., 4 (2014) 57662-57670; (d) M.A. Zolfigol, F. Afsharnadery, S. Baghery, S. Salehzadeh, F. Maleki, Catalytic applications of $\left\{[\mathrm{HMIM}] \mathrm{C}\left(\mathrm{NO}_{2}\right)_{3}\right\}$ : as a nano ionic liquid for the synthesis of pyrazole derivatives under green conditions and a mechanistic investigation with a new approach, RSC Adv., 5 (2015) 7555575568 .

[31] M.A. Zolfigol, M. Yarie, S. Baghery, Application of $\left\{\left[4,4^{\prime}-\mathrm{BPyH}\right]\left[\mathrm{C}(\mathrm{CN})_{3}\right]_{2}\right\}$ as a bifunctional nanostructured molten salt catalyst for the preparation of 2-amino-4H-chromene derivatives under solvent-free and benign conditions, Synlett, In press, Corrected proof (2016) DOI: 10.1055/s0035-1561345. 


\section{Scheme, Table and Figure section:}

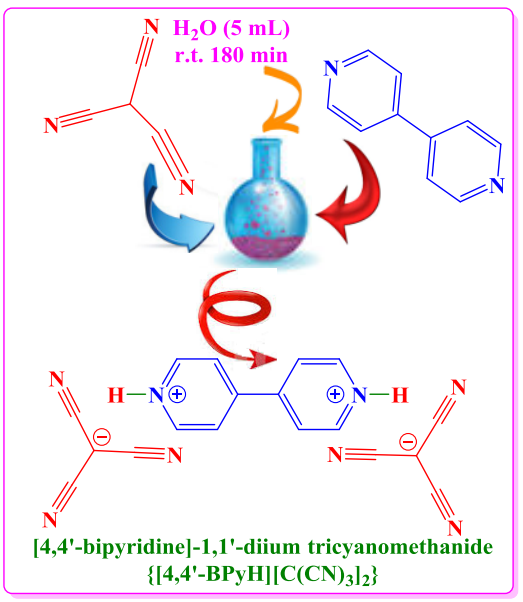

Scheme 1. The synthesis of $\left[4,4^{\prime}-\right.$-bipyridine $]-1,1^{\prime}$-diium tricyanomethanide $\left\{\left[4,4^{\prime}-\mathrm{BPyH}\right]\left[\mathrm{C}(\mathrm{CN})_{3}\right]_{2}\right\}$ as a bifunctional nano structure molten salt catalyst. 


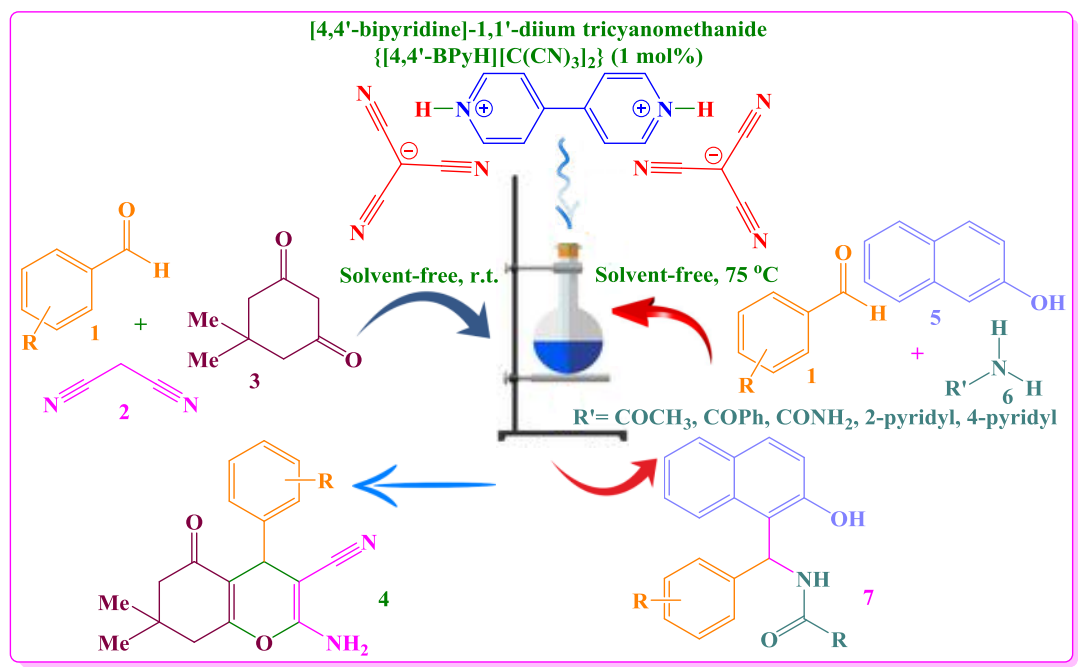

Scheme 2. The synthesis of tetrahydrobenzo[b]pyrans and amido or aminoalkyl naphthol derivatives in the presence of $\left[4,4^{\prime}-\right.$ bipyridine]-1,1'-diium tricyanomethanide $\left\{[4,4\right.$ '-BPyH $\left.]\left[\mathrm{C}(\mathrm{CN})_{3}\right]_{2}\right\}$ as a green bifunctional nano structure molten salt catalyst.

Table 1. Result of amount of the catalyst and temperature on the condensation reaction among 4-chlorobenzaldehyde, malononitrile and dimedone under solvent-free conditions. ${ }^{a}$

\begin{tabular}{ccccc}
\hline \hline Entry & Catalyst amount $(\mathrm{mol} \%)$ & Reaction temperature $\left({ }^{\circ} \mathrm{C}\right)$ & Reaction time $(\mathrm{min})$ & Yield $^{\mathrm{b}}(\%)$ \\
\hline \hline 1 & - & r.t. & 120 & 33 \\
2 & - & 100 & 120 & 33 \\
3 & 0.5 & r.t. & 60 & 81 \\
4 & 0.5 & 100 & 60 & 81 \\
5 & 1 & r.t. & 7 & 94 \\
6 & 1 & 50 & 7 & 94 \\
7 & 1 & 75 & 7 & 94 \\
8 & 1 & 100 & 7 & 94 \\
9 & 2 & r.t. & 7 & 94 \\
10 & 2 & 100 & 7 & 94 \\
11 & 5 & r.t. & 10 & 89 \\
12 & 10 & r.t. & 10 & 89 \\
\hline \hline
\end{tabular}

Reaction conditions: ${ }^{\mathrm{a}}$ 4-Chlorobenzaldehyde (1 mmol), malononitrile (1 mmol), dimedone (1 mmol); ${ }^{\mathrm{b}}$ Isolate yield. 
Table 2. The effect of numerous solvents on the reaction between 4-chlorobenzaldehyde, malononitrile and dimedone catalyzed by $\left\{\left[4,4^{\prime}-\mathrm{BPyH}\right]\left[\mathrm{C}(\mathrm{CN})_{3}\right]_{2}\right\}$ as a bifunctional NMS $(1 \mathrm{~mol} \%)$ at room temperature. ${ }^{\mathrm{a}}$

\begin{tabular}{cccc}
\hline \hline Entry & Solvent & Reaction time (min) & Yield $^{\mathrm{b}}(\%)$ \\
\hline \hline 1 & Solvent-free & 7 & 94 \\
2 & $\mathrm{H}_{2} \mathrm{O}$ & 7 & 93 \\
3 & $\mathrm{CH}_{3} \mathrm{CN}$ & 7 & 91 \\
4 & $\mathrm{C}_{2} \mathrm{H}_{5} \mathrm{OH}$ & 7 & 93 \\
5 & $\mathrm{CH}_{2} \mathrm{Cl}_{2}$ & 15 & 89 \\
6 & $\mathrm{CH}_{3} \mathrm{CO}_{2} \mathrm{Et}$ & 20 & 83 \\
7 & $n$-Hexane & 30 & 77 \\
5 & Toluene & 30 & 77 \\
\hline \hline
\end{tabular}

Reaction conditions: ${ }^{\mathrm{a}}$ 4-Chlorobenzaldehyde $(1 \mathrm{mmol})$, malononitrile $(1 \mathrm{mmol})$, dimedone $(1 \mathrm{mmol})$; ${ }^{\mathrm{b}}$ Isolate yield.

Table 3. The tandem Knoevenagel-Michael cyclocondensation reaction synthesis of tetrahydrobenzo[b]pyran derivatives using [4,4'-bipyridine $]-1,1^{\prime}$-diium tricyanomethanide $\left\{[4,4\right.$ '- $\left.\mathrm{BPyH}]\left[\mathrm{C}(\mathrm{CN})_{3}\right]_{2}\right\}$ as a bifunctional NMS catalyst. ${ }^{\text {a }}$

\begin{tabular}{llll}
\hline \hline Entry & Time (min) & Yield $^{\mathrm{b}}(\%)$ & M.p $\left({ }^{\circ} \mathrm{C}\right)[\text { [Lit. }]^{\text {Ref. }}$ (Color) \\
\hline \hline
\end{tabular}


6

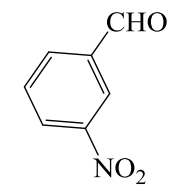

7

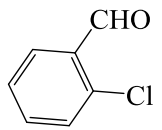

8<smiles>O=Cc1ccc(F)cc1</smiles>

9

10<smiles>COc1ccc(C=O)cc1</smiles>

10

15

10

9

8

17

14

$\mathrm{OHC}$
92

88

96

90

91

89

90

91

92

85

90
211-213 [202-204] ${ }^{16 a}$ (White solid)

212-214 [218-219] ${ }^{16 a}$ (White solid)

188-190 [178-180] $]^{16 a}$ (White solid)

195-197 [208-212] ${ }^{16 a}$ (White solid)

120-122 [183-186] ${ }^{16 a}$ (White solid)

179-181 [158-160 $]^{16 \mathrm{p}}$ (White solid)

215-217 [216-217] ${ }^{16 a}$ (White solid)

157-159 [150-152] $]^{16 a}$ (White solid)

205-207 [207-208] $]^{16 a}$ (White solid)

269-271 (White solid)<smiles>CNc1ccc(C=O)cc1</smiles> 
17<smiles>O=Cc1cccc(Cl)c1</smiles>

18

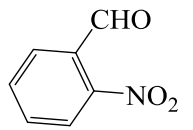

230-232 [235-237] ${ }^{16 p}$ (White solid)

235-237 [215-217] ${ }^{16 p}$ (White solid)

Reaction conditions: ${ }^{a}$ Aromatic aldehyde $(1 \mathrm{mmol})$, malononitrile $(1 \mathrm{mmol})$, dimedone $(1 \mathrm{mmol}),\left\{\left[4,4^{\prime}-\mathrm{BPyH}\right]\left[\mathrm{C}(\mathrm{CN})_{3}\right]_{2}\right\}$ as a

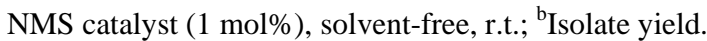

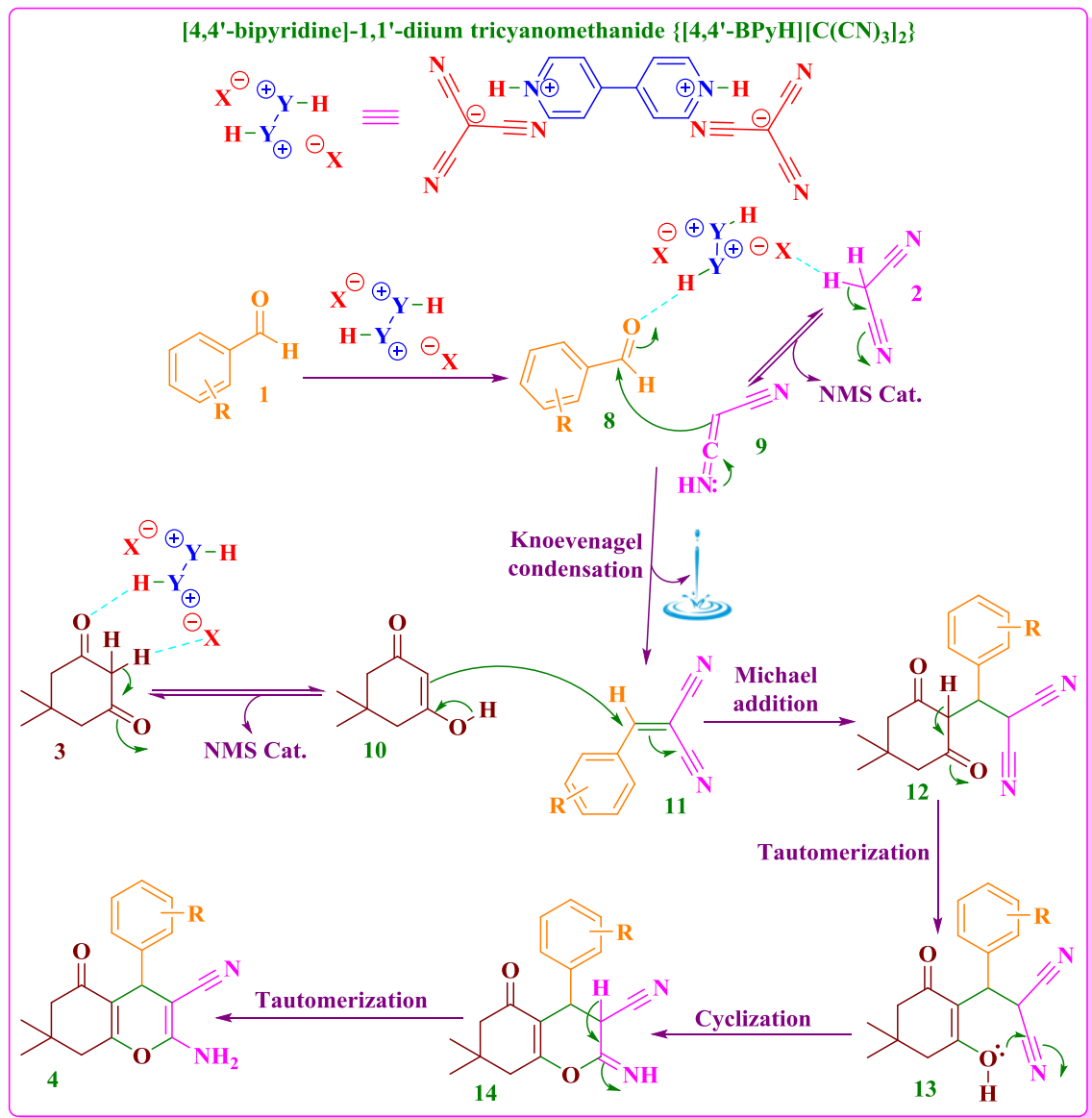

Scheme 3. The proposed mechanism for the tandem Knoevenagel-Michael cyclocondensation synthesis of tetrahydrobenzo $[b]$ pyran derivatives using $\left\{\left[4,4^{\prime}-\mathrm{BPyH}\right]\left[\mathrm{C}(\mathrm{CN})_{3}\right]_{2}\right\}$ as a bifunctional NMS catalyst.

Table 4. Reusability of $\left\{\left[4,4^{\prime}-\mathrm{BPyH}\right]\left[\mathrm{C}(\mathrm{CN})_{3}\right]_{2}\right\}$ as a bifunctional NMS catalyst on the synthesis of 2-amino-4-(4-chlorophenyl)7,7-dimethyl-5-oxo-5,6,7,8-tetrahydro-4H-chromene-3-carbonitrile. ${ }^{\mathrm{a}}$ 


\begin{tabular}{ccc}
\hline \hline Experimental errors & Time (min) & Isolated yields $^{\mathrm{b}}$ \\
\hline \hline 1 & 7 & 94 \\
2 & 8 & 93 \\
3 & 11 & 85 \\
4 & 12 & 78 \\
\hline \hline
\end{tabular}

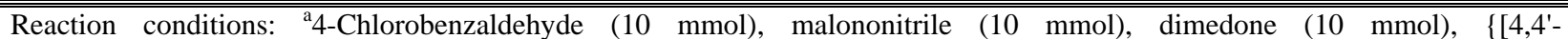

$\left.\mathrm{BPyH}]\left[\mathrm{C}(\mathrm{CN})_{3}\right]_{2}\right\}$ as a NMS catalyst (10 mol\%), Solvent-free, r.t.; ${ }^{b}$ Isolate yield.

Table 5. Result of amount of the catalyst and temperature on the condensation reaction between acetamide, 4chlorobenzaldehyde and $\beta$-naphthol under solvent-free conditions. ${ }^{2}$

\begin{tabular}{ccccc}
\hline \hline Entry & Catalyst amount $(\mathrm{mol} \%)$ & Reaction temperature $\left({ }^{\circ} \mathrm{C}\right)$ & Reaction time $(\mathrm{min})$ & Yield $^{\mathrm{b}}(\%)$ \\
\hline \hline 1 & - & r.t. & 120 & 5 \\
2 & - & 100 & 120 & 7 \\
3 & 0.5 & r.t. & 120 & 23 \\
4 & 0.5 & 100 & 60 & 25 \\
5 & 1 & r.t. & 60 & 51 \\
6 & 1 & 50 & 60 & 78 \\
7 & 1 & 75 & 20 & 93 \\
8 & 1 & 100 & 20 & 93 \\
9 & 1 & 125 & 20 & 93 \\
10 & 2 & r.t. & 60 & 51 \\
11 & 2 & 100 & 20 & 93 \\
12 & 5 & r.t. & 60 & 51 \\
13 & 5 & 100 & 20 & 93 \\
\hline \hline
\end{tabular}

Reaction conditions: ${ }^{a}$ 4-Chlorobenzaldehyde $(1 \mathrm{mmol}), \beta$-naphthol $(1 \mathrm{mmol})$, acetamide $(1 \mathrm{mmol})$; ${ }^{\mathrm{b}}$ Isolate yield.

Table 6. Reaction of acetamide, 4-chlorobenzaldehyde and $\beta$-naphthol catalyzed using $\left\{\left[4,4^{\prime}-\mathrm{BPyH}\right]\left[\mathrm{C}(\mathrm{CN})_{3}\right]_{2}\right\}$ as a bifunctional NMS (1 mol\%) in various solvents under reflux conditions. Reaction was done under solvent-free condition at $75{ }^{\circ} \mathrm{C} .{ }^{a}$

\begin{tabular}{cccc}
\hline \hline Entry & Solvent & Reaction time (min) & Yield $^{\mathrm{b}}(\%)$ \\
\hline \hline 1 & Solvent-free & 20 & 93 \\
2 & $\mathrm{H}_{2} \mathrm{O}$ & 60 & 18 \\
3 & $\mathrm{CH}_{3} \mathrm{CN}$ & 45 & 78 \\
4 & $\mathrm{C}_{2} \mathrm{H}_{5} \mathrm{OH}$ & 60 & 35 \\
5 & $\mathrm{CH}_{2} \mathrm{Cl}_{2}$ & 60 & 71 \\
6 & $\mathrm{CH}_{3} \mathrm{CO}_{2} \mathrm{Et}$ & 60 & 29
\end{tabular}




\begin{tabular}{cccc}
7 & $n$-Hexane & 60 & 15 \\
5 & Toluene & 60 & 21 \\
\hline \hline
\end{tabular}

496

497

498

499

500

501

502

503

Reaction conditions: ${ }^{\mathrm{a}} 4-$ Chlorobenzaldehyde $(1 \mathrm{mmol}), \beta$-naphthol $(1 \mathrm{mmol})$, acetamide $(1 \mathrm{mmol}) ;{ }^{\mathrm{b}}$ Isolate yield.

Table 7. The synthesis of amino or amidolalkyl naphthol derivatives in the presence of [4,4'-bipyridine]-1,1'-diium

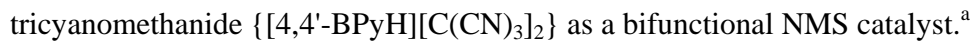

\begin{tabular}{cccc}
\hline \hline Entry & Time (min) & ${\text { Yield }{ }^{\mathrm{b}} \text { (\%) }}_{\text {M.p }\left({ }^{\circ} \mathrm{C} \text { ) [Lit. }\right]^{\text {Ref. }} \text { (Color) }}$ \\
243-245 [248-250] ${ }^{25}$ (Yellow \\
solid)
\end{tabular}


8<smiles>O=Cc1ccc(Cl)cc1</smiles>

9<smiles>O=Cc1ccc(Cl)cc1</smiles>

2-Pyridyl

4-Pyridyl

COMe

$\mathrm{COPh}$

$\mathrm{CONH}_{2}$

2-Pyridyl

14<smiles>COc1ccc(C=O)cc1</smiles>

15

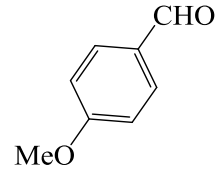

16

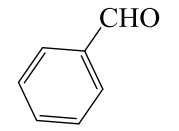

25

30

20

15

25

30

35

20

35
88

171-173 [161-163] $]^{25}$ (White solid)

93

solid)

201-203 [209-2211] ${ }^{26}$ (Cream

217-219 [218-220] ${ }^{26}$ (Cream solid)

274-276 [280-282] $]^{25}$ (White solid)

264-266 [271-273] ${ }^{25}$ (Cream solid)

203-205 [206-208] $]^{25}$ (Cream solid)

163-165 [172-174] ${ }^{26}$ (Cream solid)

253-255 [263-265] ${ }^{26}$ (Cream solid)

181-183 [177-179] ${ }^{25}$ (White solid)

Reaction conditions: ${ }^{a}$ Aromatic aldehyde $(1 \mathrm{mmol}), \beta$-naphthol $(1 \mathrm{mmol})$, amine or amide derivatives $(1 \mathrm{mmol}),\{[4,4$ '$\mathrm{BPyH}]\left[\mathrm{C}(\mathrm{CN})_{3}\right]_{2}$ \} as a NMS catalyst $(1 \mathrm{~mol} \%)$, solvent-free, $75^{\circ} \mathrm{C}$; ${ }^{b}$ Isolate yield. 


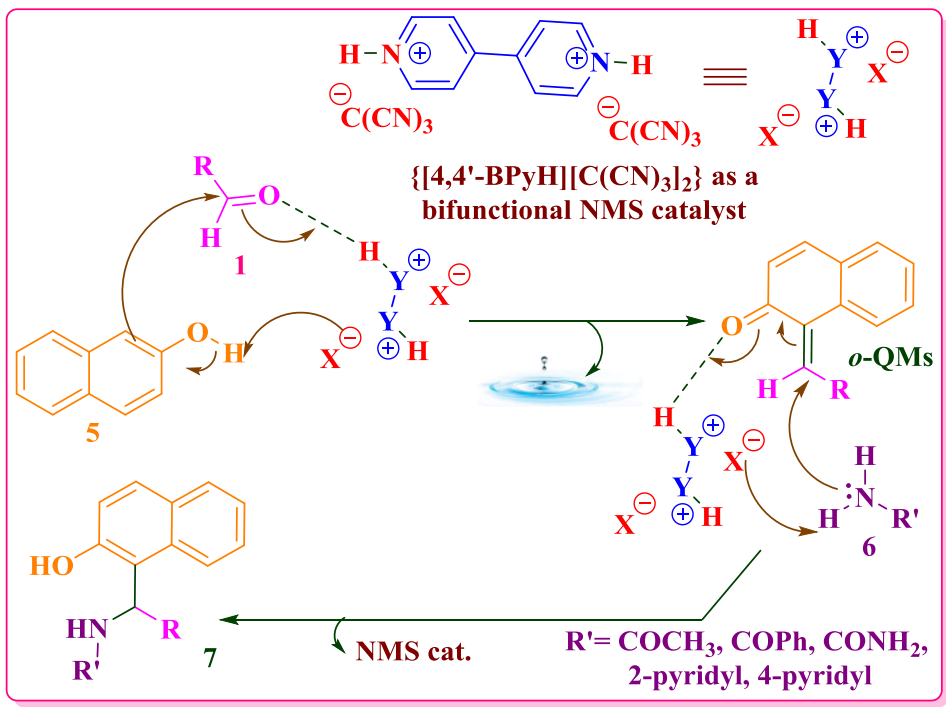

Scheme 4. Suggested mechanism for the synthesis of amido or aminoalkyl naphthol derivatives using $\left\{\left[4,4^{\prime}-\mathrm{BPyH}\right]\left[\mathrm{C}(\mathrm{CN})_{3}\right]_{2}\right\}$ as a NMS catalyst.

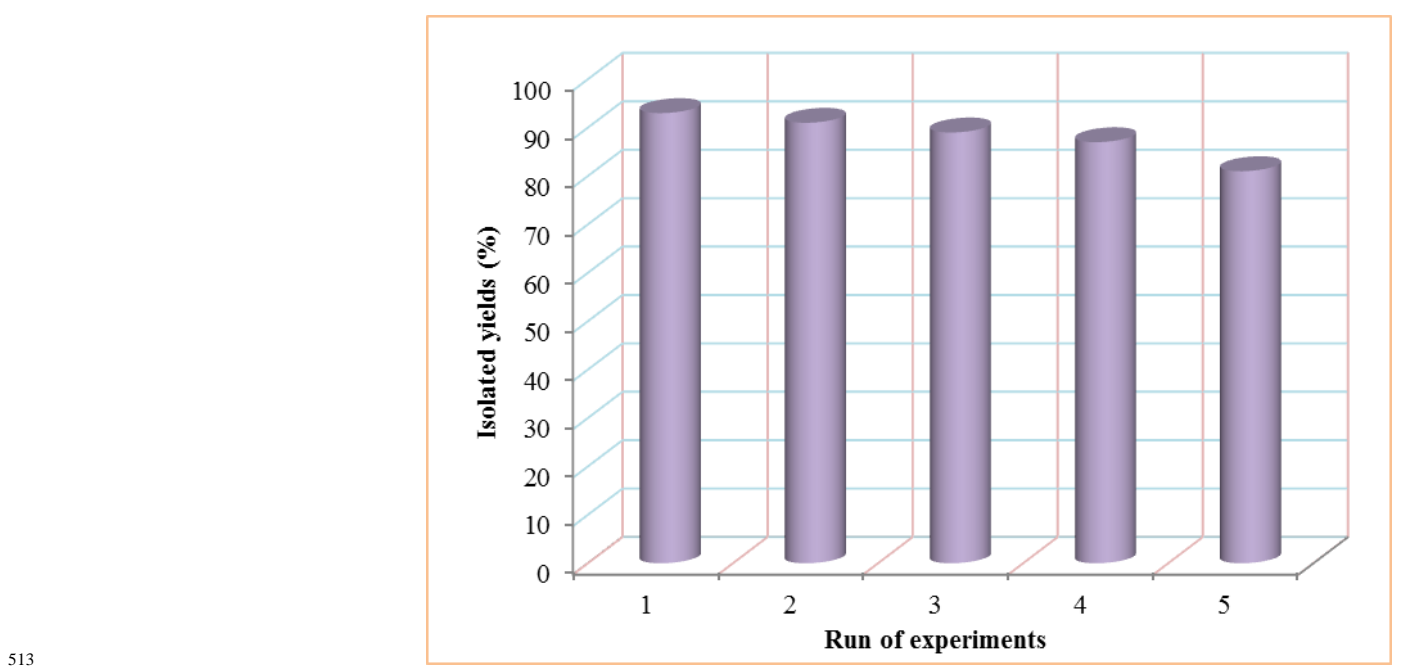

Fig. 1. Reusability of the NMS catalyst in 20 minutes in the synthesis of corresponded amidoalkyl naphthol. 
[4,4'-Bipyridine]-1,1'-diium tricyanomethanide as a nanostructured molten salt and its catalytic application in the synthesis of tetrahydrobenzo[b]pyrans, amido and aminoalkyl naphthol derivatives

Mohammad Ali Zolfigol,* Meysam Yarie, Saeed Baghery

Department of Organic Chemistry, Faculty of Chemistry, Bu-Ali Sina University, Hamedan 6517838683, Iran

*Corresponding Author: Fax: +988138257407

E-mail:zolfi@basu.ac.irandmzolfigol@yahoo.com (M.A.Zolfigol).

\section{Graphical Abstract}

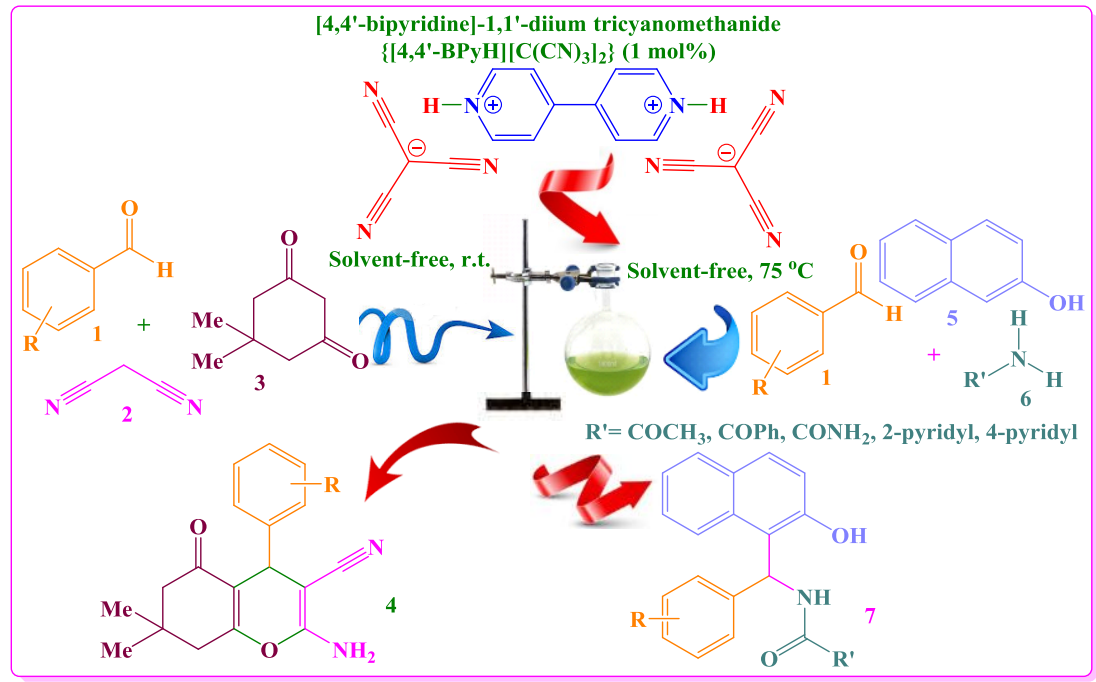

